\title{
Persistent accumulation of unrepaired DNA damage in rat cortical neurons: nuclear organization and ChIP-seq analysis of damaged DNA
}

Jorge Mata-Garrido ${ }^{1}$, Olga Tapia ${ }^{1}$, Iñigo Casafont ${ }^{1}$, Maria T. Berciano ${ }^{1,3}$, Ana Cuadrado ${ }^{2 *}$ and Miguel Lafarga ${ }^{1,4^{*}}$ (D)

\begin{abstract}
Neurons are highly vulnerable to DNA damage induced by genotoxic agents such as topoisomerase activity, oxidative stress, ionizing radiation (IR) and chemotherapeutic drugs. To avert the detrimental effects of DNA lesions in genome stability, transcription and apoptosis, neurons activate robust DNA repair mechanisms. However, defective DNA repair with accumulation of unrepaired DNA are at the basis of brain ageing and several neurodegenerative diseases. Understanding the mechanisms by which neurons tolerate DNA damage accumulation as well as defining the genomic regions that are more vulnerable to DNA damage or refractory to DNA repair and therefore constitute potential targets in neurodegenerative diseases are essential issues in the field. In this work we investigated the nuclear topography and organization together with the genome-wide distribution of unrepaired DNA in rat cortical neurons 15 days upon IR. About 5\% of non-irradiated and 55\% of irradiated cells accumulate unrepaired DNA within persistent DNA damage foci (PDDF) of chromatin. These PDDF are featured by persistent activation of DNA damage/repair signaling, lack of transcription and localization in repressive nuclear microenvironments. Interestingly, the chromatin insulator CTCF is concentrated at the PDDF boundaries, likely contributing to isolate unrepaired DNA from intact transcriptionally active chromatin. By confining damaged DNA, PDDF would help preserving genomic integrity and preventing the production of aberrant proteins encoded by damaged genes. ChIP-seq analysis of genome-wide $\mathrm{\gamma H} 2 \mathrm{AX}$ distribution revealed a number of genomic regions enriched in $\mathrm{\gamma H} 2 \mathrm{AX}$ signal in IR-treated cortical neurons. Some of these regions are in close proximity to genes encoding essential proteins for neuronal functions and human neurodegenerative disorders such as epm2a (Lafora disease), serpini1 (familial encephalopathy with neuroserpin inclusion bodies) and il1 rp/1 (mental retardation, X-linked 21). Persistent $\mathrm{\gamma H} 2 \mathrm{AX}$ signal close to those regions suggests that nearby genes could be either more vulnerable to DNA damage or more refractory to DNA repair.
\end{abstract}

Keywords: DNA damage- ionizing radiation- cortical neurons- persistent DNA damage foci- transcription silencingCTCF- $\gamma$ H2AX genomic distribution, Neurodegenerative diseases

\footnotetext{
* Correspondence: acuadrado@cnio.es; lafargam@unican.es

${ }^{2}$ Chromosome Dynamics Group, Molecular Oncology Program, Spanish

National Cancer Research Centre (CNIO), 28029 Madrid, Spain

'Department of Anatomy and Cell Biology and "Centro de Investigación

Biomédica en Red sobre Enfermedades Neurodegenerativas" (CIBERNED),

University of Cantabria-IDIVAL, Santander, Spain

Full list of author information is available at the end of the article
}

(c) The Author(s). 2018 Open Access This article is distributed under the terms of the Creative Commons Attribution 4.0 International License (http://creativecommons.org/licenses/by/4.0/), which permits unrestricted use, distribution, and reproduction in any medium, provided you give appropriate credit to the original author(s) and the source, provide a link to the Creative Commons license, and indicate if changes were made. The Creative Commons Public Domain Dedication waiver (http://creativecommons.org/publicdomain/zero/1.0/) applies to the data made available in this article, unless otherwise stated. 


\section{Introduction}

Neuronal DNA damage with generation of double strand breaks (DSBs) occurs physiologically as a result of transcription by means of the activity of topoisomerase complexes, which cut transiently both DNA strands to release torsional stress. [13, 37, 47, 72, 74]. As a consequence, repair of such topoisomerase II-induced DNA damage represents an endogenous threat for gene expression and may lead to unrepaired DNA accumulation and generation of transcriptional errors potentially harmful for the cell $[26,27]$. An additional source of endogenous neuronal DNA damage is the oxidative stress produced by the high rate of oxygen consumption, which leads to increased generation of reactive oxygen species with age [73]. Mammalian neurons are also highly vulnerable to exogenous genotoxic agents such as chemotherapy drugs and ionizing radiations (IRs) normally used in cancer treatment [7, 50]. Such vulnerability to DNA damage is in part mediated by the relaxed chromatin conformation characteristic in neurons, that facilitates the access of genotoxic agents to DNA strands [50, 53].

Unrepaired DNA accumulation results in loss of genome integrity and the subsequent increased risk of errors in the manufacture of both RNA and protein products [13, 27]. Such increase of unrepaired DNA lesions might contribute to the ageing process: for instance, an age-dependent decline in DNA repair activity has been observed in the rodent and human brain, and defects in DNA repair may cause premature aging [23, $43,45,73,79]$. Persistent accumulation of DNA damage has also been linked to several neurodegenerative diseases both in human patients and experimental animal models [3, 36, 48, 52, 59, 67]. In fact, oxidative DNA damage is emerging as a hallmark in Alzheimer's and Parkinson's diseases [44, 69].

DSBs are detrimental for neurons as they profoundly impact on genome integrity, transcriptional activity, cellular proteostasis and energy starvation $[7,21,27,48,50$, 59]. They are repaired by non-homologous end joining (NHEJ) since in post-mitotic neurons there is not a normal sister chromatid sequence that serves as a template. NHEJ is more error-prone than homologous recombination and small deletions can be introduced during the DSB ends processing before religation $[13,41]$.

In a previous study, using a model to induce DSBs in peripheral nervous system neurons of the rat sensory ganglia by means of IR with X-rays (4 Gy), we demonstrated that the neuronal DNA damage response (DDR) involves the formation of two types of DNA-damage/repair chromatin domains [7]. The first type is featured by transient and abundant small foci that disappear within the $24 \mathrm{~h}$ post-IR, reflecting a rapid and effective DNA repair crucial for neuronal survival. The second consists of one to three large and persistent DNA damage foci (PDDF) that accumulate unrepaired DNA for several weeks post-IR [7]. Importantly, PDDF preserve DNA damage signaling and repair factors, are transcriptionally silent and associate with repressive nuclear environments.

To expand on the aforementioned study in peripheral nervous system neurons, we aimed to determine whether the accumulation of unrepaired DNA in PDDF is a general cellular event that also affects neurons of the central nervous system, in particular, cerebral cortex neurons. With this purpose we investigated the nuclear organization and fate of unrepaired DNA accumulated in PDDF of cortical neurons 15 days upon irradiation (4 Gy). We also wanted to define the identity of the genomic sequences enriched within PDDF. With this purpose, we used ChIP-seq to obtain the genome-wide distribution of $\gamma \mathrm{H} 2 \mathrm{AX}$, which specifically recognizes the damaged DNA accumulated in these neuronal foci $[7$, 50]. Our results show that the DDR pattern observed in cortical neurons reproduces the structural, spatial, molecular and transcriptional organization of the PDDF present in peripheral nervous system neurons, suggesting a common long-term response of mammalian neurons to DSB lesions. Moreover, ChIP-seq analysis of damaged DNA in PDDF identifies a number of genomic regions enriched in $\gamma \mathrm{H} 2 \mathrm{AX}$ signal, some of them in close proximity to genes encoding essential proteins for neuronal functions and neurodegenerative disorders. Importantly, since the expression of some of these genes appears affected both in control and, to a higher extent, in irradiated neurons, our ChIP-seq has allowed to identify genes either more vulnerable to DNA damage or more refractory to DNA repair, which are potential targets in neurodegenerative diseases.

\section{Materials and methods \\ Animals}

Experiments were designed and performed to minimize the use of animals. A total of 42 young male SpragueDawley rats, distributed in a control (non-irradiated, $n=21$ ) and X-ray irradiated animals $(n=21)$, and 6 young male C57 mice (non-irradiated, $n=3$; irradiated, $n=3$ ) were used. Irradiated animals received a single dose of $4 \mathrm{~Gy}$ of ionizing radiation (IR). Animals were housed with a $12 \mathrm{~h}$ light/dark cycle and had free access to food and water. They were kept, handled, and sacrificed according with the directives of the Council of the European Communities and current Spanish legislation, and the experiments were approved by the Bioethical Committee of the University of Cantabria.

\section{X-ray irradiation}

Exogenous DNA damage was induced by X-Ray irradiation using an X-Ray generator system (Maxishot-d, Yxlon, Int. USA) equipped with an X-Ray tube that 
works at $200 \mathrm{kV}$ and $4.5 \mathrm{~mA}$. The animals, deeply anesthetized with pentobarbital $(50 \mathrm{mg} / \mathrm{kg})$, were protected with a lead tube, exposing only the head, and the beam focused on the head to avoid adverse effects produced by global animal radiation. Animals received a single sub-lethal dose of 4Gy, a reference dose in DNA damage/repair experiments [7, 50]. Control and irradiated animals were sacrificed 15 days (15d) post-IR and the cerebral cortex was isolated and processed for different cell biology and biochemical procedures.

\section{Immunofluorescence and confocal microscopy}

For light immunocytochemistry, animals $(n=3$ per experimental condition) deeply anesthetized as described above were perfused with the fixative solution containing 3.7\% formaldehyde (freshly prepared from paraformaldehyde) in PBS. Tissue fragments from the parietal cortex were removed and washed in PBS. Each tissue fragment was transferred to a drop of PBS on a siliconized slide (SuperFrostPlus, Menzel-Gläser, Germany) and squashed preparations of dissociated neurons were performed following the previously reported procedure [61]. In addition to dissociated neuron preparations we performed $7 \mu \mathrm{m}$-thick formaldehyde-fixed cryosections from the parietal cortex. All samples were sequentially treated with $0.1 \mathrm{M}$ glycine in PBS for $15 \mathrm{~min}, 3 \% \mathrm{BSA}$ in PBS for 30 min and $0.5 \%$ Triton X-100 in PBS for 45 min. They were then incubated with primary antibodies overnight at $4 .{ }^{\circ} \mathrm{C}$, washed with $0.05 \%$ Tween 20 in PBS, incubated for $45 \mathrm{~min}$ in the specific secondary antibody conjugated with FITC or Cy3 (Jackson, USA), washed in PBS and mounted with the antifading medium ProLong (Thermo Fisher Scientific). Some samples were counterstained with Propidium Iodide (Thermo Fisher Scientific), a cytochemical marker of nucleic acids.

Confocal images were obtained with a LSM510 (Zeiss, Germany) laser scanning microscope using a $63 \times$ oil (1.4 NA) objective. To avoid overlapping signals, images were obtained by sequential excitation at 488 and $543 \mathrm{~nm}$ in order to detect FITC and Cy3, respectively. Images were processed using Photoshop software.

The quantitative analysis of the i) proportion of damaged cortical neurons containing IR-induced PDDF, ii) mean number of foci per nucleus within the population of PDDF-containing neurons, and iii) nuclear topography of PDDF in three nuclear regions (perinucleolar, adjacent to heterochromatin clumps and nuclear interior) was performed in dissociated rat cortical neurons. Samples were immunostained for $\gamma \mathrm{H} 2 \mathrm{AX}$, counterstained with propidium iodide and directly examined throughout different focal planes using a $40 \times$ objective and fluorescence microscopy (Axioskop 2 plus, Zeiss, Germany). At least 100 neurons per animal were examined ( $n=3$ animals per experimental condition). Image processing and measurement steps were performed on ImageJ, public domain software for image analysis $(\mathrm{NIH}$, Bethesda, Maryland, USA; http://rsb.info.nih.gov/ij/). Average values were pooled for subsequent graphing and analysis. Data were analyzed using Microsoft Excel and the analysis of variance was used to determine the statistical significance of differences between control and irradiated neurons of sensory ganglia. Values are Means SD.

\section{Transmission and immunoelectron microscopy}

For conventional and immunogold electron microscopy examination of cortical neurons, control and irradiated rats ( $n=3$ animals per group) were perfused under deep anesthesia with $3.7 \%$ paraformaldehyde in $0.1 \mathrm{M}$ cacodylate buffer for $10 \mathrm{~min}$ at room temperature. Small tissue fragments from the parietal cortex were washed in $0.1 \mathrm{M}$ cacodylate buffer, dehydrated in increasing concentrations of methanol at $-20{ }^{\circ} \mathrm{C}$, embedded in Lowicryl $\mathrm{K} 4 \mathrm{M}$ at $-20{ }^{\circ} \mathrm{C}$ and polymerized with ultraviolet irradiation. Ultrathin sections were mounted on nickel grids, stained with lead citrate and uranyl acetate and examined with a JEOL 1011 electron microscope. For immunogold electron microscopy, sections were sequentially incubated with $0.1 \mathrm{M}$ glycine in PBS for $15 \mathrm{~min}$, $5 \%$ BSA in PBS for 30 min and the primary antibody for $2 \mathrm{~h}$ at $37{ }^{\circ} \mathrm{C}$. After washing, sections were incubated with the specific secondary antibodies coupled to $10 \mathrm{~nm}$ gold particles (BioCell, UK; diluted 1:50 in PBS containing $1 \%$ BSA). Following immunogold labeling, grids were stained with lead citrate and uranyl acetate. As controls, ultrathin sections were treated as described omitting the primary antibody.

\section{In situ run-on transcription assay}

Active transcription sites were labeled by incorporation of 5'-fluorouridine (5'-FU) into nascent RNA. Briefly, anesthetized control and irradiated rats $(n=3$ animals per group) were given an intravenous injection of 5 '-FU (Sigma, UK) from a stock solution of 0.4 M 5'-FU in $0.9 \%$ saline at $5 \mu \mathrm{l} / \mathrm{g}$ doses. All animals were sacrificed at 45 min post-injection and fixed by perfusion with $3.7 \%$ paraformaldehyde in HPEM buffer (2× HPEM: Hepes, $60 \mathrm{mM}$; Pipes, $130 \mathrm{mM}$; EGTA, $20 \mathrm{mM}$; and $\mathrm{MgCl}_{2} \cdot 6 \mathrm{H}_{2} \mathrm{O}, 4 \mathrm{mM}$ ) containing $0.5 \%$ Triton X-100 for $10 \mathrm{~min}$. Tissue samples from the parietal cortex were removed, washed in HPEM buffer containing 0.5\% Triton X-100 for $10 \mathrm{~min}$, dehydrated in increasing concentrations of methanol at $-20{ }^{\circ} \mathrm{C}$, embedded in Lowicryl $\mathrm{K} 4 \mathrm{M}$ at $-20{ }^{\circ} \mathrm{C}$ and polymerized with ultraviolet irradiation. Ultrathin sections were mounted on nickel grids and sequentially incubated with $0.1 \mathrm{M}$ glycine in PBS for $15 \mathrm{~min}, 5 \% \mathrm{BSA}$ in PBS for $30 \mathrm{~min}$ and the mouse monoclonal anti-BrdU (clone BU-33, Sigma, UK) antibody (diluted $1 / 25$ in $50 \mathrm{mM}$ Tris- $\mathrm{HCl}, \mathrm{pH}$ 7.6, 
containing $1 \%$ BSA and $0.1 \mathrm{M}$ glycine) for $1 \mathrm{~h}$ at $37{ }^{\circ} \mathrm{C}$. After washing, sections were incubated with an anti-mouse secondary antibody coupled to $15 \mathrm{~nm}$ gold particles (BioCell, UK; diluted 1:50 in PBS containing 1\% BSA). Following immunogold labeling, grids were stained with lead citrate and uranyl acetate and examined with a JEOL 1011 electron microscope. As controls, ultrathin sections were treated as described in absence of the primary antibody.

\section{SDS-PAGE and immunoblotting}

Tissue samples of the parietal cortex from control and irradiated rats ( $n=3$ animals per group) were lysed using a Polytron PT-2000 (Kinematica ${ }^{\oplus}$, Luzern-Switzerland) on ice in cold extraction buffer NETN [20 mM Tris- $\mathrm{HCl}$ $\mathrm{pH}$ 8.0, $500 \mathrm{mM} \mathrm{NaCl}, 1 \mathrm{mM}$ EDTA] containing Benzonase $(1 \mu \mathrm{L} / \mathrm{mL}$ lysis buffer) (Novagen), supplemented with protease and phosphatase inhibitor cocktail (Halt ${ }^{\mathrm{TM}}$ Protease and Phosphatase inhibitor single use cocktail, Thermo Scientific, USA) and incubated for $30 \mathrm{~min}$ on ice. After centrifugation (12 $\mathrm{min}$ at $12000 \mathrm{rpm})$ at $4{ }^{\circ} \mathrm{C}$ the supernatant was frozen. Proteins were separated on SDS-PAGE gels and transferred to nitrocellulose membranes by standard procedures. Protein bands were detected with an Odyssey ${ }^{\text {Ts }}$ Infrared-Imaging System (Li-Cor Biosciences) according to Odyssey ${ }^{\text {тм }}$ Western-Blotting Protocol. Immunoblots were developed with anti-mouse IRDye800DX or anti-rabbit IRDye700DX (Rockland Immunochemicals, USA) secondary antibodies.

\section{ChIP-seq and ChIP-qPCR analysis}

Chromatin immunoprecipitation (ChIP) of the parietal cortex neurons from control and irradiated rats $(n=2$ animals per group) was performed as described [16], with some modifications. 20 million cells per condition were cross-linked with $1 \%$ formaldehyde added to the media for $15 \mathrm{~min}$ at RT. After quenching with $0.125 \mathrm{M}$ Glycine, fixed cells were washed twice with PBS containing $1 \mu \mathrm{M}$ PMSF and protease inhibitors, pelleted and lysed in lysis buffer (1\%SDS, $10 \mathrm{mM}$ EDTA, $50 \mathrm{mM}$ Tris- $\mathrm{HCl} \mathrm{pH} \mathrm{8.1)} \mathrm{at} 2 \times 10^{7}$ cells $/ \mathrm{ml}$. Sonication was performed with a Covaris system (shearing time $20 \mathrm{~min}$, $20 \%$ duty cycle, intensity 6, 200 cycles per burst and $30 \mathrm{~s}$ per cycle). $10^{7}$ cells equivalent to $40-50 \mu \mathrm{g}$ of chromatin were used per immunoprecipitation reaction with $10 \mu \mathrm{g}$ of anti-histone H2AX phospho-Ser139 or anti-CTCF (07-729, Millipore). For ChIP-seq, 5 ng of immunoprecipitated chromatin (as quantitated by fluorometry) were electrophoresed on an agarose gel and independent sample-specific fractions of 100-200 bp were taken. Adapter-ligated library was completed by limited-cycle PCR with Illumina PE primers (11 to 13 cycles). DNA libraries were applied to an Illumina flow cell for cluster generation and sequenced on the Illumina Genome
Analyzer IIx (GAIIx). Image analysis was performed with Illumina Real Time Analysis software (RTA1.8).

Alignment of 40-bp long sequences to the reference genome (RGSC6.0/rn6 rat genome) was performed using Bowtie1 (http://bowtie-bio.sourceforge.net/index.shtml) under default settings. Duplicates were removed using Picardtools (version 1.60) and peak calling was carried out using MACS2 (version 2.1.1.20160309) setting a q value (FDR) to 0.05 using the '--extsize' argument with the values obtained in the 'macs 2 predictd' step. Sample C1 was used as control for both conditions I1 and I2.

Mean read density profiles and read density heatmaps for different chromatin binding proteins were generated with deepTools 2.0 [65] using BAM files of processed reads and plotting them around peak summits called in control condition.

ChIP-qPCR on immunoprecipitated chromatin was performed using the SYBR Green PCR Master Mix and an ABI Prism ${ }^{\circ} 7900 \mathrm{HT}$ instrument (Applied Biosystems ${ }^{\oplus}$ ). Primers were designed using OligoPerfect Designer $^{\mathrm{Tm}}$ (Invitrogen) and reactions were performed in triplicate. Chromosome coordinates of the positions in the study and the corresponding primers are listed in Additional file 1: Table S1. The relative amount of each amplified fragment was estimated with respect to the amplification obtained from input DNA, and normalized against the binding to a negative region in the "Control 1 " condition using the $\Delta \Delta \mathrm{Ct}$ method.

\section{Antibodies}

The following primary antibodies were used. Mouse monoclonal antibodies anti-histone H2AX phospho-Ser139 (1/1000 Western, 1/200 immunostaining; Millipore-Upstate 05-636, MA, USA), anti-BrdU (1/25 immunostaining; Sigma B8434, UK), anti-WRAP53 (1/200 immunostaining; Abnova H00055135-M04, USA), anti-UBF (1/100 immunostaining; Santa Cruz Biotechnology SC-13125) and anti-B23 (1/100 immunostaining; Abcam ab10530). Rabbit polyclonal antibodies anti-histone H2AX phospho-Ser139 (1/200 immunostaining; Novus Biologicals NB100-384), anti-trimethyl-histone H4 (Lys 20) (1/250 immunostaining; Millipore-Upstate 07-463, USA), anti-53BP1 (1/100 immunostaining; Bethyl Laboratories A300-272A, Inc., USA), anti-CTCF (1/100 immunostaining; Millipore-Upstate 07-729, MA, USA), anti- Iba1 (1/500 immunostaining; Wako 019-19,741), anti-GFAP (1/500 immunostaining; Thermo Fisher Scientific PA3-16727), anti-NeuN (1/100 immunostaining; Abcam ab177487) and anti-Histone H3 (1/2000 Western; Thermo Fisher Scientific PA5-16183). Chicken polyclonal anti- $\beta$-galactosidase (1/200 immunostaining; Abcam ab9361). Specific secondary antibody conjugated with FITC or TexasRed were used (Jackson Lab., USA). 


\section{Results}

Organization of PDDF induced by IR in cortical neurons The organization of PDDF was analyzed in dissociated cortical neuron perikarya and cerebral cortex cryosections from rats and mice exposed to a single dose (4 Gy) of IR, known to induce DSBs [7], and examined 15d post-IR. Immunolabeling preparations for the phosphorylated histone $\mathrm{H} 2 \mathrm{AX}(\gamma \mathrm{H} 2 \mathrm{AX})$, a well-established marker of DSBs [19, 33], counterstained with propidium iodide revealed the presence of $\gamma \mathrm{H} 2 \mathrm{AX}$-positive PDDF in cortical neurons from both species (Fig. 1a-c). PDDF-containing cells were identified as neurons by their large and euchromatic nuclei, prominent nucleoli and distribution of protein synthesis machinery in the Nissl substance (Fig. 1a-c) and further confirmed with immunostaining for the neuronal marker NeuN (Fig. 1d, e). PDDF were found in cortical neurons of different sizes, suggesting that persistent DNA damage occurs in several neuronal types within the cerebral cortex. Moreover, PDDF were not detected in glial cells neither astrocytes nor microglia (GFAP or Iba1 positive, respectively, Fig. 2a, b). It is known that persistent DNA damage induces a senescence-like phenotype in neurons [22]. To explore whether the formation of PDDF was associated with senescence we performed $ß$-galactosidase immunolabeling in cerebral cortex cryosections. We found very few $ß$-galactosidase-positive cells, all of them featured by the typical microglial filigrane cytoplasmic processes, and the absence of PDDF (Fig. 2c).

To compare PDDF formation between non-irradiated and irradiated rats, dissociated cortical neurons were immunolabeled for $\gamma \mathrm{H} 2 \mathrm{AX}$ and 53BP1, an essential protein that promotes DNA repair by the NHEJ $[4,60]$. 53BP1 showed a general and diffuse nuclear pattern that excludes the nucleolus in control non-irradiated cells (Fig. 3a, g). In control neurons $\gamma \mathrm{H} 2 \mathrm{AX}$ - and 53BP1-positive PDDF were infrequent (less than 5\%) and likely correspond to spontaneous DNA damage (Fig. 3a, d). In contrast, one or a very few PDDF immunoreactive for $\gamma \mathrm{H} 2 \mathrm{AX}$ and 53BP1 were found in about $55 \%$ of cortical neurons at $15 \mathrm{~d}$ post-IR (Fig. 3b, d, h). Among the population of cortical neurons with DNA damage, the mean number of PDDF per nucleus was 1.5 in irradiated neurons and 1.2 in non-irradiated ones (Fig. 3e). In addition to $\gamma \mathrm{H} 2 \mathrm{AX}$ and 53BP1, PDDF concentrated WRAP53 (WD40 encoding RNA antisense to p53) (Fig. 3i), an essential protein for DDR that provides a scaffold for DNA repair factors [31]. The persistence of DNA damage was confirmed by Western blotting performed with cerebral cortex lysates, were a significant increase in the expression level of $\gamma \mathrm{H} 2 \mathrm{AX}$ was detected at $15 \mathrm{~d}$ post-IR (Fig. 3c). Our data prove the persistence in PDDF of
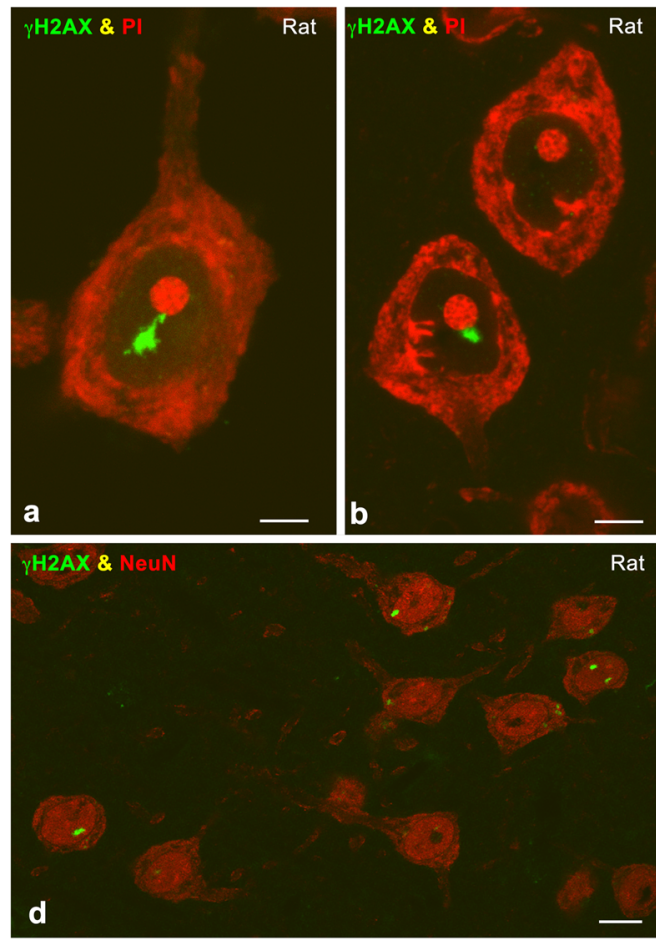
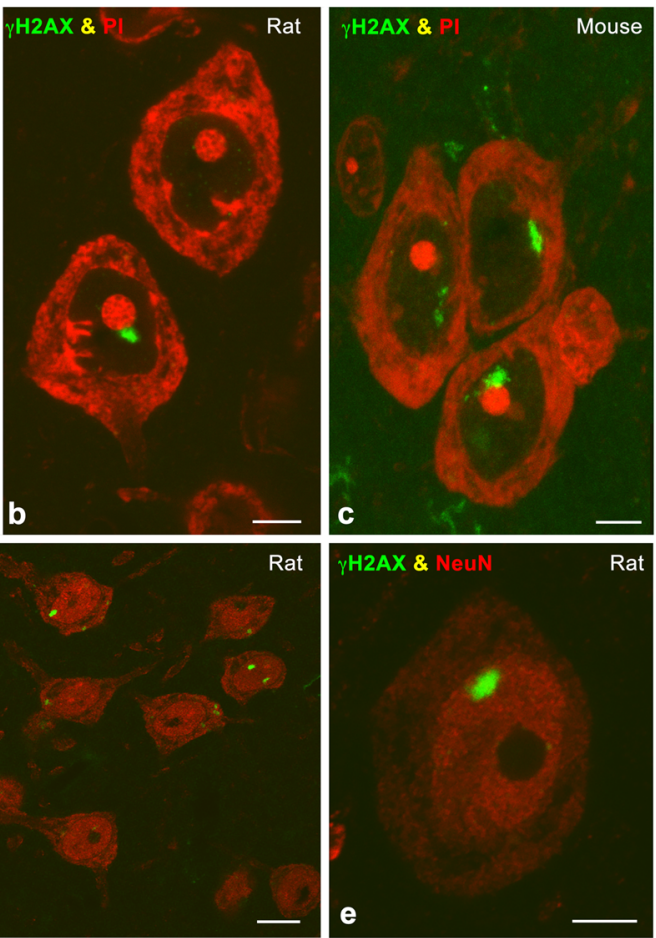

Fig. 1 a-c Representative examples of immunolabeling for $\mathrm{yH} 2 \mathrm{AX}$ of cortical neurons in a dissociated neuron preparation (a) and cryosections $(\mathbf{b}, \mathbf{c})$ counterstained with propidium iodide (PI) from irradiated rat $(\mathbf{a}, \mathbf{b})$ and mouse $(\mathbf{c})$ at 15 days post-IR. Note the presence of typical PDDF associated with the nucleolus. $\mathbf{d}$, e Rat cerebral cortex cryosections double immunolabeled for $\mathrm{YH} 2 \mathrm{AX}$ and NeuN illustrate the specific localization of PDDF in NeuN-positive neurons at 15 days post-IR. Scale bars: a-c, e, $5 \mu \mathrm{m}$; d, $10 \mu \mathrm{m}$ 


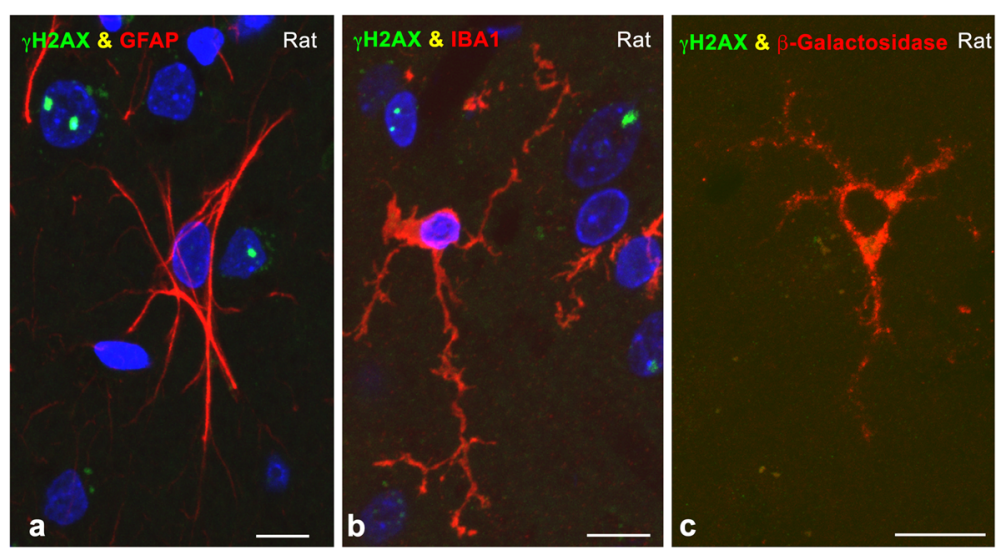

Fig. 2 a, b Cerebral cortex cryosections double immunolabeled for $\mathrm{YH} 2 \mathrm{AX}$ and GFAP (a) or Iba1 (b) showing the absence of PDDF in an astrocyte and a microglial cell from irradiated rats at 15 days post-IR. Some neuronal nuclei of different size counterstained with DAPI contain $\gamma$ H2AX-positive PDDF. c Cerebral cortex cryosection illustrating a ß-galactosidase-positive senescent microglial cell free of $\gamma \mathrm{H} 2 \mathrm{AX}$-positive PDDF at 15 days post-IR. Scale bars: $10 \mu \mathrm{m}$

essential components of the DDR indicating that DNA damage/repair signaling can last in the long term after IR.

Since PDDF nuclear topology affects their possible interactions with other nuclear compartments, we analyzed PDDF distribution in three nuclear domains: perinucleolar, peripheral and nuclear interior. Our results indicate an organized distribution of PDDF within the neuronal nucleus: Approximately $70 \%$ of them were perinucleolar, $25 \%$ were distributed at the nuclear periphery and the rest were located in the nuclear interior (Fig. 3f). This preferential association of PDDF with the nucleolus was confirmed in cortical neurons immunostained for $\gamma \mathrm{H} 2 \mathrm{AX}$ in combination with two nucleolar markers, upstream binding factor (UBF) and nucleophosmin/B23, [32, 58] (Fig. 3j, k). PDDF located at the nuclear periphery or nuclear interior were frequently associated with a heterochromatin mass positive for the histone H4K20me3, a marker of repressed chromatin domains [68], (Fig. 3l).

\section{PDDF compartmentalization and boundaries in cortical neurons}

To define the structural nature of PDDFs we performed immunogold electron microscopy experiments to detect the DNA repair factor 53BP1. PDDF appear as cleared chromatin compartments within euchromatin regions, featured by a loose network of chromatin fibers. Their electro-lucent appearance, decompacted chromatin conformation and well-defined boundaries with adjacent euchromatin, makes the PDDF a distinct nuclear compartment (Fig. 4a). High magnification analysis showed that immunogold particles specifically localize over the network of chromatin fibers within PDDF (Fig. 4a, inset). This observation suggests that the PDDF contain chromatin regions with increased accessibility to DNA-damage repair factors.
PDDF transcriptional activity was determined by means of an in situ transcription assay performed at ultrastructural level. Active transcription was observed in euchromatic domains upon a 45-min pulse of 5'-FU (Fig. 4b). In contrast, PDDF appeared as transcription-free chromatin compartments that lacked nascent RNA. Interestingly, transcriptional activity was observed in their flanking euchromatin, establishing a sharply defined boundary between intact euchromatin, that is transcriptionally permissive, and DNA-damaged chromatin, which is transcriptionally silent (Fig. 4b).

To further understand the molecular organization of PDDF boundaries we performed light and electron microscopy immunocytochemistry to investigate whether CTCF (CCCTC binding factor) is involved in the architectural organization of PDDF. CTCF is an insulator protein that, together with cohesin complex, is responsible for the chromatin folding in Topologically Associating Domains (TADs), submegabase segments that tend to self-associate and define discrete transcriptionally related regions $[17,46$, 54]. Our immunocytochemical analysis showed a diffuse pattern of nuclear CTCF binding that is specifically enriched at the borders between PDDFs and the adjacent euchromatin where prominent CTCF-positive microfoci were visible (Fig. 4c-e). Immunogold electron microscopy confirmed CTCF enrichment at the euchromatin flanking PDDF, and a reduced CTCF density inside these regions (Fig. 4f, g). Our findings agree with recently published data supporting that CTCF-dependent chromatin structure is essential to define the chromatin sensitivity to DNA damage [5].

Genome-wide distribution of $\mathrm{YH} 2 \mathrm{AX}$ in IR treated cortical neurons reveals persistent DNA damage in specific genomic regions

We wondered then if persistent DNA damage could be located in genomic regions known to be crucial for 

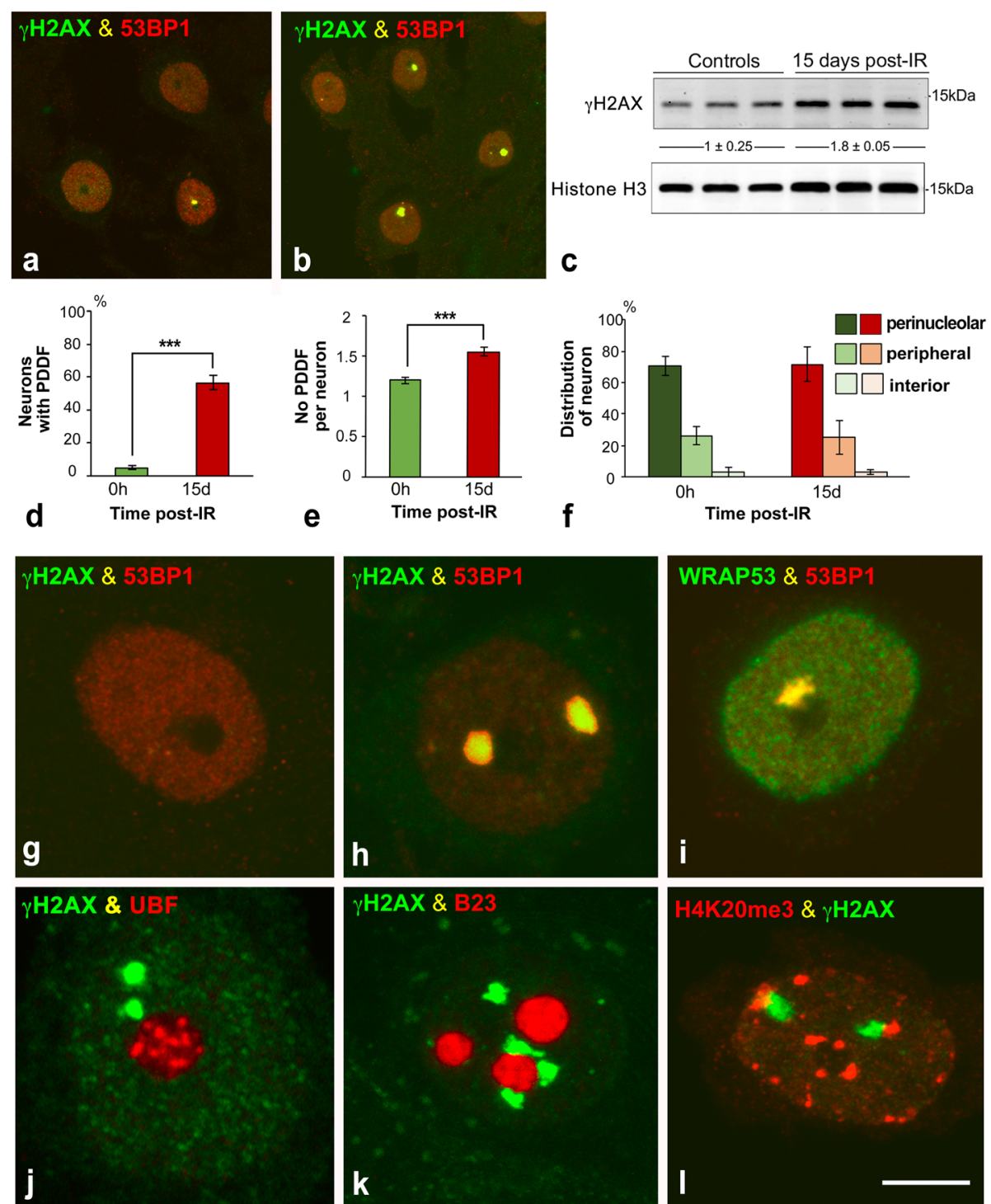

Fig. 3 a, b Representative examples of double immunolabeling for $\gamma \mathrm{H} 2 \mathrm{AX}$ and 53BP1 in dissociated cortical neurons from non-irradiated (a) and irradiated rats (15d post-IR) (b). Some neurons exhibited a PDDF immunolabeled for $\mathrm{HH} 2 \mathrm{AX}$ and 53BP1. Scale bar: $5 \mu \mathrm{m}$. $\mathbf{c}$ Western blot analysis of YH2AX in parietal cortex lysates from non-irradiated and irradiated rats ( $n=3$ animals per group). Protein levels of $\gamma \mathrm{H} 2 \mathrm{AX}$ were increased upon DNA-damage induced IR. The expression of histone H3 was used as protein loading control, and the fold increase estimated. $\mathbf{d}$ Proportion of cortical neurons containing $\mathrm{YH} 2 \mathrm{AX}$-positive PDDF in non-irradiated and irradiated neurons. (*** $p<0.001$ by Student's $t$ test). e Mean number of PDDF per nucleus within the PDDF-containing neuronal population. $\left(^{*} p<0.05\right.$ by Student's $t$ test). $\mathbf{f}$ Distribution of PDDF in three nuclear regions: perinucleolar, nuclear periphery and nuclear interior. Approximately 70\% of PDDF were spatially associated with the nucleolus in both non-irradiated

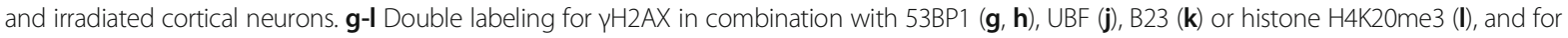
53BP1 in combination with WRAP53 (i) illustrating the concentration of $\mathrm{YH} 2 \mathrm{AX}, 53 \mathrm{BP} 1$ and WRAP53 in PDDF, and the spatial association of PDDF with the nucleolus (j, k) and with heterochromatin masses (I). g: non-irradiated neuron. h-I: irradiated neurons at 15 days post-IR. Scale bar: $5 \mu \mathrm{m}$

neuronal physiology and homeostasis. Since $\gamma \mathrm{H} 2 \mathrm{AX}$ is specifically located in PDDFs, we reasoned that $\gamma \mathrm{H} 2 \mathrm{AX}$ containing regions would correspond to the part of the genome located in these domains. To address this issue, we performed ChIP-seq analysis in cells from cerebral cortex of control and irradiated rats. In order to be sure about the specificity of the $\gamma \mathrm{H} 2 \mathrm{AX}$ binding regions, we performed ChIP-seq in two independent biological replicates of irradiated cells (I1 and I2 in Fig. 5). Moreover, we sequenced about 60 million reads per condition to ensure enough genomic coverage resulting in approximately 30 to 42 million of uniquely aligned reads that defined $665 \mathrm{\gamma H} 2 \mathrm{AX}$ peaks in control cells and a slightly higher number of positions in irradiated cells (1022 and 846) with a FDR $<0.05$ (Fig. 5a). The vast majority $(90 \%)$ of the $\gamma \mathrm{H} 2 \mathrm{AX}$ positions found in control 


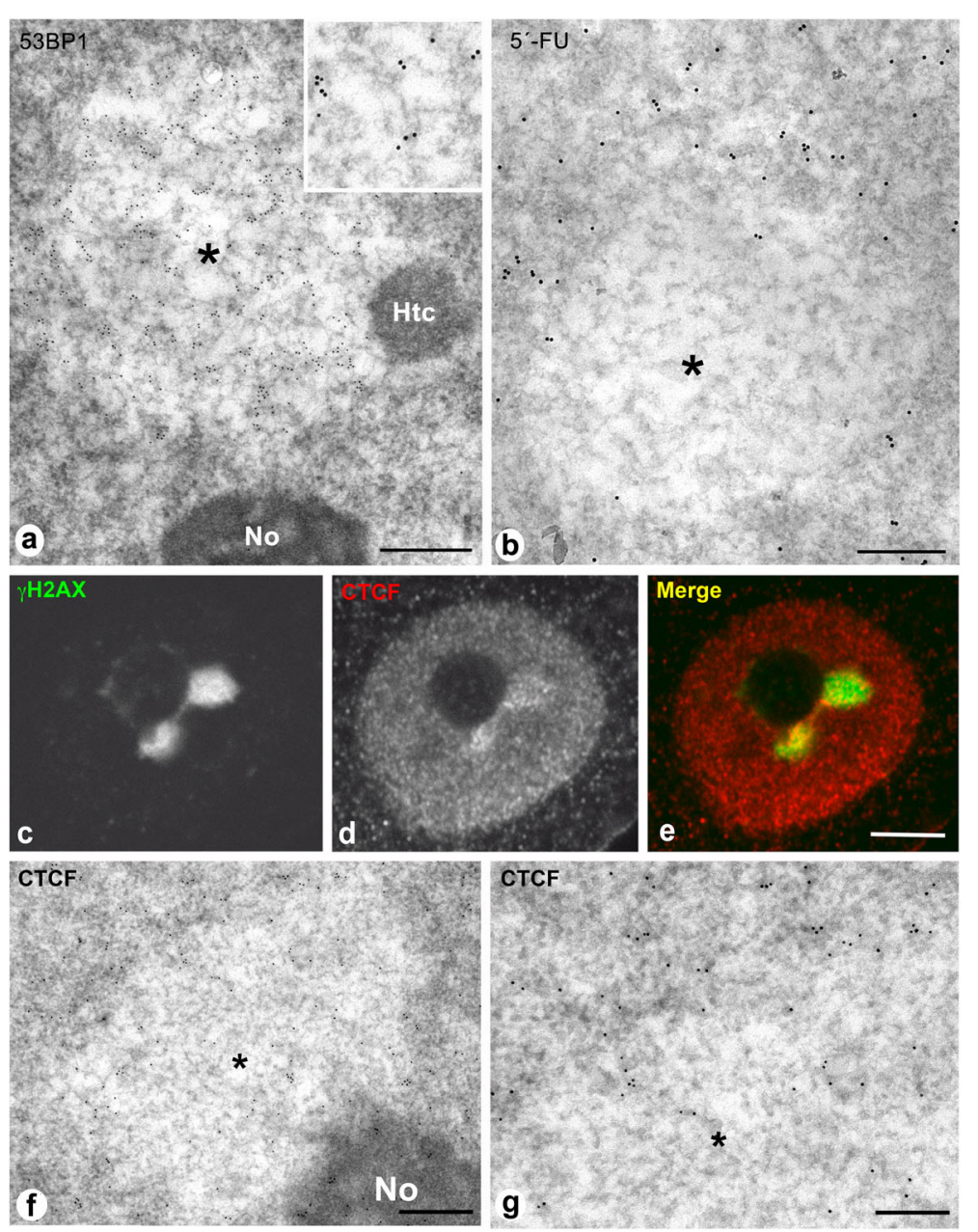

Fig. 4 a Immunogold electron microscopy for 53BP1 of a typical PDDF (asterisk) in a rat cortical neuron. It is composed of a loosen network of chromatin fibers decorated with gold particles and appears associated with the nucleolus (No) and a heterochromatin mass (Htc). 15 days post-IR. Scale bar: 500 nm Inset: High magnification of 53BP1-immunolabeled chromatin fibers. $\mathbf{b}$ In situ electron microscopy transcription assay illustrating the incorporation of $5^{\prime}$-fluorouridine (5'-FU) into nascent RNA after 45 min of the administration of the halogenated nucleotide. Note the absence of $5^{\prime}$-FU incorporation in the PDDF (asterisk) and its incorporation in the transcriptionally active adjacent euchromatin. Rat cortical neuron after 15 days post-IR. Scale bar: $300 \mathrm{~nm}$. c-e Representative example of double immunolabeling for $\mathrm{YH} 2 \mathrm{AX}$ and CTCF in an irradiated cortical neuron showing two perinucleolar PDDF. In addition to a diffuse nuclear distribution of CTCF, this insulator protein appears concentrated in numerous microfoci at the periphery of the YH2AX-positive PDDF. 15 days post-IR. Scale bar: 3 mm. f, g Immunogold electron microscopy for the CTCF shows its preferential distribution at the PDDF boundary with euchromatin, although some scattered gold particles appear within the PDDF (asterisk). No: nucleolus. Scale bars: f, 450 nm; g, 250 nm

cells were also present in irradiated neurons, confirming the existence of genomic regions with higher damage sensitivity (Venn diagrams in Fig. 5a). Importantly, 80\% of the $\gamma \mathrm{H} 2 \mathrm{AX}$ peaks defined in $\mathrm{I} 2$ cells coincided with those in I1 replicate, supporting the robustness and reliability of our analysis. Read density analysis further sustained not only the conservation of $\gamma \mathrm{H} 2 \mathrm{AX}$ genomic distribution among conditions, but also the persistency of increased $\gamma \mathrm{H} 2 \mathrm{AX}$ levels in cells 15d upon irradiation (Fig. 5b). The analysis of the regions specifically enriched in irradiated cells with Panther software revealed that some of them were located at close distance or within the gene body of genes involved in essential functions for neuronal homeostasis, including neurotransmission, synaptic plasticity and adhesion, pentose phosphate pathway, autophagy-lysosomal pathway and protein quality control (Fig. 5c, Additional file 2: Figure S1a and Table 1). In addition, we have identified three genes (olr551, vom1r24 and vom 2r41) encoding olfactory receptors, which are relevant for olfaction in rodents. The characterization of $\gamma \mathrm{H} 2 \mathrm{AX}$ binding sequences suggests that PDDFs contain some cell-specific genes that are normally expressed in neurons. Importantly, 16 of these genes appeared in the OMIM (Online Mendelian Inheritance in Man) catalog of human genes implicated in genetic phenotypes of certain human diseases, most of them neurological and neuropsychiatric diseases (Table 1). They include neurological disorders such as 
a
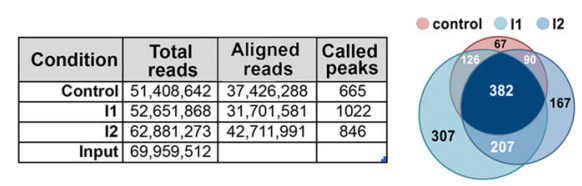

b
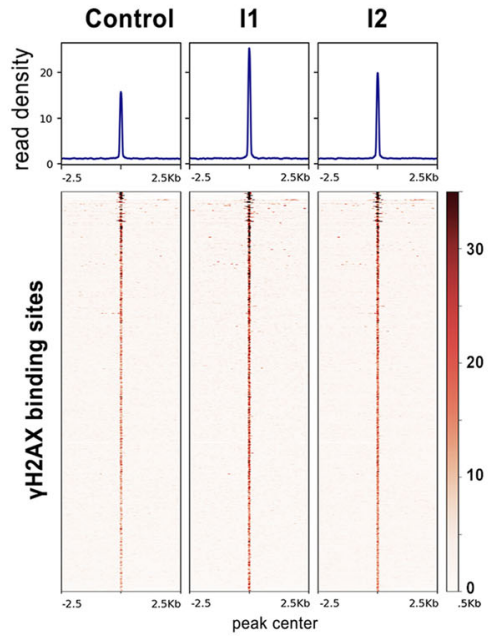

d

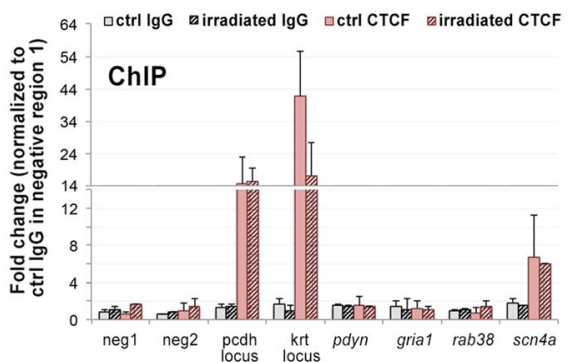

C

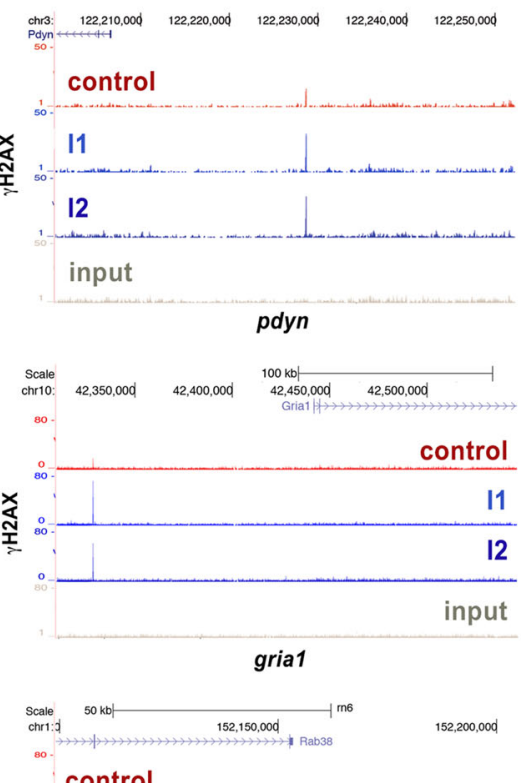

control

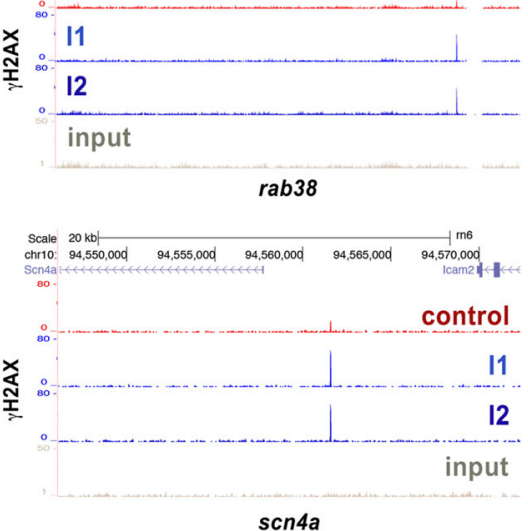

Fig. 5 Genome wide distribution of $\mathrm{yH} 2 \mathrm{AX}$ in rat cortical neurons $15 \mathrm{~d}$ upon IR shows persistent DNA damage in specific genomic regions. a Table shows the number of total reads, uniquely aligned reads and called peaks for control and irradiated (I1 and I2) rat cortical neurons. Venn diagram shows the overlap (at least one nucleotide) between the called peaks defined in the different conditions. $\mathbf{b}$ Read density plots and heatmaps show genome-wide $\gamma \mathrm{H} 2 \mathrm{AX}$ distribution in the conditions described in a. c UCSC browser images showing $\gamma \mathrm{H} 2 \mathrm{AX}$ binding in different genomic regions close to neuronal specific processes and pathologies. $\mathbf{d}$ ChIP-qPCR analysis of CTCF enrichment around several $\mathrm{YH} 2 \mathrm{AX}$ binding sites defined by ChIP-seq. Immunoprecipitation with rabbit IgG was performed to ensure antibody specificity. Neg1 and neg2 correspond to genomic regions with undetectable $\mathrm{H} \mathrm{H} 2 \mathrm{AX}$ binding. Pcdh and krt loci were used as positive CTCF binding sites. Graph represents the results of two independent biological replicates performed in triplicates.

Lafora disease $(e p m 2 a)$, encephalopathy familial with neuroserpin inclusion bodies (serpini1), mental retardation X-linked 21 (illrpl1) and hyperkalemic periodic paralysis $(\operatorname{scn} 4 a)$.

To better define the features of the DNA damage regions found in our analysis we investigated their co-localization with the insulator protein CTCF by ChIP-qPCR. We based on the high degree of conservation between CTCF binding sites among species [71] to infer positive CTCF binding sites in rat cortical neurons. With this aim, we used CTCF and cohesins SMC1 and
SA1 ChIP-seq data from adult mouse cortex [16] to select two strong CTCF binding sites (pcdh and krt loci) whose binding region shared more than $80 \%$ of identity with the corresponding region in the rat genome (Additional file 2: Figure S1b) and that were used as positive controls for CTCF enrichment. Our ChIP-qPCR analysis revealed that the $\gamma \mathrm{H} 2 \mathrm{AX}$ binding site located close to scn $4 a$ promoter indeed colocalizes with CTCF (Fig. 5d), suggesting that at least a fraction of the DNA damage sensitive sites found in our study might be related to topological restraints. 
Table 1 YH2AX-binding genomic regions specifically enriched in PDDF from cortical neurons and related to human genes implicated in neurological and neuropsychiatric disorders

\begin{tabular}{|c|c|c|c|c|}
\hline Gene & Encoded protein & $\begin{array}{l}\text { Fold } \\
\text { change }\end{array}$ & Relation to human pathology & Reference \\
\hline aga & Aspartylglucosaminidase & 2.875 & Aspartylglucosaminuria (0.69) & [34] \\
\hline appl2 & $\begin{array}{l}\text { Adaptor protein containing Ph domain, } \\
\text { Ptb domain and leucine zipper motif } 2\end{array}$ & 3.31 & Substance adiction (0.2) & [18] \\
\hline cdh10 & Cadherin 10 & 2.88 & Autism (0.2) & [78] \\
\hline epm2a & Laforin glucan phosphatase & 2.25 & Lafora disease (0.71), progressive myoclonus epilepsy (0.407) & {$[1,24]$} \\
\hline fbxo30/fbxw7 & F-box/WD repeat containing protein 7 & 2.25 & Glioma (0.127), genome instability (0.12) & {$[8,75]$} \\
\hline grial & Glutamate receptor 1 & 3.72 & $\begin{array}{l}\text { Schizophrenia (0.208), Bipolar Disorder (0.206), Mental Depression } \\
\text { and Depressive disorder (0.201), learning and memory disorders (0.2) }\end{array}$ & $\begin{array}{l}{[10,40,51,} \\
70]\end{array}$ \\
\hline gria2 & Glutamate receptor 1 & 2.69 & $\begin{array}{l}\text { Schizophrenia (0.209), Bipolar Disorder (0.203), Depressive disorder } \\
(0.201)\end{array}$ & {$[9-11]$} \\
\hline htrla & Serotonin $5-\mathrm{Ht}-1 \mathrm{~A}$ receptor $1 \mathrm{~A}$ & 2.72 & $\begin{array}{l}\text { Mental Depression and Depressive disorder (0.253), Schizophrenia } \\
(0.221)\end{array}$ & {$[42,77]$} \\
\hline$i 116$ & Interleukin 1- $\beta$ & 2.39 & Alzheimer disease (0.369) & [80] \\
\hline il1 rap/1 & $\begin{array}{l}\text { Interleukin } 1 \text { receptor accessory } \\
\text { protein-like } 1\end{array}$ & 2.375 & Autism (0.404), Mental retardation (0.205) & {$[30,66]$} \\
\hline lbr & Lamin b receptor & 2.39 & Reynold syndrome (0.6) & [25] \\
\hline rab38 & Ras-related protein Rab-38 & 3.38 & Frontotemporal dementia (0.12) & [20] \\
\hline $\operatorname{scn} 4 a$ & $\begin{array}{l}\text { Sodium channel protein type } \\
4 \text { subunit alpha }\end{array}$ & 3.19 & $\begin{array}{l}\text { Hyperkalemic periodic paralysis }(0.688) \text {, Potassium-aggravated myotonia } \\
(0.602), \text { Hypokalemic periodic paralysis type } 2(0.48) \text {, Hypokalemic periodic } \\
\text { paralysis type } 1(0.41) \text {, Congenital paramyotonia }(0.408) \text {, Fluctuating } \\
\text { myotonia }(0.24) \text {, Myotonia }(0.405)\end{array}$ & [6] \\
\hline serpinil & Neuroserpin & 2.88 & $\begin{array}{l}\text { Familial encephalopathy with neuroserpin inclusion bodies (0.681), } \\
\text { Dementia (0.208), Progressive myoclonus epilepsy }(0.203)\end{array}$ & [15] \\
\hline sugct & $\begin{array}{l}\text { Succinyl-CoA; Glutarate-CoA } \\
\text { transferase }\end{array}$ & 3.71 & Migraine (0.24) & [63] \\
\hline tkt & Transketolase & 2.23 & Wernicke-Korsakoff syndrome, Wernicke encephalopaty (0.201) & [14] \\
\hline
\end{tabular}

The number in brackets that appears next to the name of diseases corresponds to the "Score of the reliability of the gene-disease pair, based on the type and number of sources where is reported, and the number of PMIDs"

\section{Discussion}

Increasing evidence supports a role for the accumulation of unrepaired DNA in the ageing process [23, 43, 79] and in the pathogenesis of neurodegenerative disorders $[22,36,48,52,59]$. Our study provides the first analysis of the long-term nuclear compartmentalization and genomic localization of unrepaired DNA in rodent healthy cerebral cortex neurons that have been exposed to IR. Here, we found that generation of DSBs in rat and mouse cortical neurons by IR induces de novo formation of a chromatin compartment, the PDDF [7, 50]. We demonstrate that PDDF are neuron-specific structures, as shown by their exclusive presence in cells with the typical neuronal morphology of perikarya [62] that express the neuronal marker NeuN. PDDF delimitate genomic regions in which chromatin conformation cannot be restored to its normal pre-damage state due to persistent DSBs that are difficult to repair or not reparable at the long term $[48,79]$. The absence of PDDF in astrocytes and microglia suggests that glial cells are either more resistant to irradiation or more efficient to repair
DNA damage. Interestingly, senescence-like state induced by DNA damage [22] seems not to be correlated with PDDF formation upon irradiation, at least under the experimental conditions used in this study.

The organization pattern of PDDF in cortical neurons is similar to that observed in sensory ganglion neurons of the peripheral nervous system under similar experimental conditions [50]. This fact strongly supports that central and peripheral mammalian neurons share a similar pattern of DDR, resulting in the accumulation of unrepaired DNA in a specific nuclear compartment, the PDDF.

The presence of PDDFs in most cortical neurons at $15 \mathrm{~d}$ post-IR indicates that unrepaired DNA sequences from different chromosomes, as revealed the ChIP-seq analysis, move from over relatively large distances to be concentrated in one or two isolated chromatin compartments. Increased chromatin mobility at sites of IR-induced DSBs has been previously reported by tracking the fluorescently tagged DNA repair factor 53BP1 in living mammalian cells [38]. In line with this, recent 
work has revealed that $53 \mathrm{BP} 1$ promotes the mobility of damaged chromatin [81].

PDDF appeared as cleared chromatin domains with a decompacted structure composed of loosely organized chromatin fibers $[39,50]$. This configuration likely provides DNA repair factors a better access to damaged DNA, as suggested by the 53BP1 immunogold labeling of chromatin fibers within PDDF. Interestingly, although PDDF exhibit an open chromatin structure, which is in principle permissive to gene expression, they are transcription-free nuclear compartments. Transcriptional silencing at PDDF could thus be a protective neuronal mechanism aimed to reduce genomic instability specifically in neurons by preventing the production of aberrant mRNAs and proteins encoded by damaged genes [50]. It is important to consider that neurons rapidly repair most DNA lesions within $24 \mathrm{~h}$ post-IR to promote cell survival [7] and that the NHEJ DNA repair pathway is error-prone and occasionally works at the expense of small deletions and mutations that can provoke transcriptional errors [13, 27, 79]. Thus, in spite of the protective role of PDDF, those transcriptional errors can lead to neuronal dysfunction by affecting the cellular proteostasis [27].

An important challenge is to understand how neurons tolerate DNA damage accumulation without triggering neurodegeneration and cell death in spite of the numerous DSBs induced upon a single dose of IR $[7,50]$. Our results suggest that PDDF are specialized nuclear centers for long-term sequestration of unrepaired DNA, which maintain the neuronal DNA damage/repair signaling $(\gamma \mathrm{H} 2 \mathrm{AX}$ and 53BP1) and prevent the expression of damaged genes. By sequestering damaged DNA, PDDF would help protecting genomic integrity and avoid transcription of undamaged chromatin, therefore contributing to neuronal survival. Since mammalian neurons are diploid cells [61], the transcriptional blockade of the genes located in the genomic regions contained within the PDDF could potentially be compensated by the expression of the second copy of the gene. In fact, our in situ transcription assay reveals that transcription is preserved in undamaged euchromatin, including the flanks of PDDF.

One important issue is to understand how the specific structural, molecular and transcriptional features of the PDDF, delimited by their well-defined boundaries, are established. Genome-wide interaction studies by chromosome conformation capture techniques have shown that the genome is organized in Topologically Associated Domains (TADs) that constitute discrete regulatory units within which enhancers and promoters interact $[17,55]$. TADs are separated by boundary regions that often have cohesin and CTCF [17]. Disruption of CTCF binding sites by CRISP/Cas9 genome editing impairs the insulation activity of TAD boundaries and provokes changes in the enhancer-promoter interaction profile that leads to changes in transcription [28, 46]. Our findings showing CTCF enrichment at PDDF borders as well as its colocalization with the $\gamma \mathrm{H} 2 \mathrm{AX}$ binding site defined upstream the $s c n 4 a$ gene points to a role of CTCF, likely in cooperation with cohesin complex, in the definition of the interface between healthy and damaged chromatin. In agreement with this, it has been recently published that chromatin loop anchors bound by CTCF and cohesin are specially vulnerable to DSBs induced by topoisomerase 2B [5]. These data indicate that there is a narrow relationship between chromatin architecture and topological stress. Moreover, the insulation function of CTCF at the PDDF boundaries might be necessary for transcriptional repression and active clustering of damaged DNA sequences. In cortical neurons, this mechanism could contribute to tolerate the accumulation of unrepaired DNA in an insulated compartment without triggering apoptotic pathways. This idea is supported by experiments performed in a different cellular model, where CTCF boundaries located in repressive heterochromatin domains separate enhancers from promoters thus silencing transcription [64].

PDDF are not randomly distributed inside the nuclear volume of cortical neurons; rather than that, they have a preferential spatial association with the nucleolus and, to a lower extent, with the heterochromatin masses located at the nuclear periphery. In both localizations PDDF are closely associated to a repressive nuclear environment [64]. In mammalian neurons, such repressive environment is specifically generated by the clustering of centromeric and telomeric heterochromatin domains at the nucleolar surface and nuclear periphery $[2,49]$. It is well established that repressed heterochromatin is enriched in silencing proteins such as the methylated DNA-binding protein $\mathrm{MeCP} 2$ and polycomb repressive complexes (PRC1 and PRC2) whose presence at those positions can silence nearby genes [2,64]. Localization of PDDF adjacent to a repressive environment might facilitate the selective silencing of damaged genes, as revealed by the in situ transcription assay, thus contributing to preserve genomic stability. Moreover, several lines of evidence indicate that nucleolar and heterochromatin DSBs can move towards the periphery of both structures for DNA repair looking for the more permissive environment constituted by euchromatin [12, 29, 35, 76]. This raises the possibility that PDDFs could also be involved in DNA repair of ribosomal genes and heterochromatin sequences.

A major finding of this study is the genome-wide identification of DNA sequences enriched in PDDF from cortical neurons. Given the specific binding of $\gamma \mathrm{H} 2 \mathrm{AX}$ to damaged chromatin within PDDF, we assume that our ChIP-seq signal corresponds to genomic regions located inside this nuclear compartment. To our knowledge this is the first study characterizing the genomic 
distribution of neuronal unrepaired DNA accumulated in nuclear foci. Importantly, our analysis revealed that $\gamma \mathrm{H} 2 \mathrm{AX}$ was already present in certain genomic positions in non-irradiated neurons and that upon irradiation, its levels increase to a different extent depending on the regions, ranging from 1.5 to 7.5 fold. This observation is consistent with our results in cortical neurons (present study) and previous data from sensory ganglion neurons [50] that show that approximately 5\% of non-irradiated neurons exhibit PDDFs, indicating that young adult neurons can accumulate unrepaired DNA for long-term under physiological conditions. Based on this, we envision that there could be a set of genes which, by virtue of their genomic distribution in chromatin domains, are more vulnerable to DNA damage or more refractory to DNA repair and whose unrepaired DNA accumulates in PDDFs. This hypothesis is supported by their increased vulnerability to IR exposure, as shown by the higher levels of $\gamma \mathrm{H} 2 \mathrm{AX}$ observed in irradiated cerebral cortex samples.

It has been proposed that neurons, as post-mitotic cells, avoid repairing their whole genome and limit to repair specifically a few genes through a mechanism that is coupled to their transcription [56, 57]. Transcription of these genes is important for maintenance of trophic functions required for neuronal survival. However, our results indicate that most of $\gamma \mathrm{H} 2 \mathrm{AX}$ located close to protein-coding genes correspond to cellular pathways essential for neuronal homeostasis, such as neurotransmission, synaptic plasticity and adhesion, pentose phosphate pathway or autophagy-lysosomal pathway. This suggests that at least a set of actively transcribed genes could be inefficiently repaired, and remain at PDDFs.

In addition to ageing, defective DNA repair and concomitant DNA damage accumulation has been linked with several neurodegenerative disorders [13, 48, 52, 73]. However, understanding the pathogenic mechanisms of DNA damage requires the identification of those genes with higher propensity to accumulate lesions in neuropathological conditions. A major challenge is to identify the DNA lesions essential for the progression of each neurodegenerative disease by using experimental animal models in which the accumulation of DNA damage mimics partially the pathogenesis of the human disease [48]. In this regard, our $\gamma \mathrm{H} 2 \mathrm{AX}$ ChIP-seq analysis identifies a number of genes with nearby DNA lesions in both non-irradiated and irradiated samples, suggesting that they are more susceptible to be damaged. Some of these genes are cataloged in OMIM and DisGeNET platforms as associated with genetic human diseases, with special focus in neurological and neuropsychiatric disorders. Among those related with neurological disorders, epm $2 a$ (Lafora disease), serpini1 (encephalopathy familial with neuroserpin inclusion bodies), il1rpl1 (autism and mental retardation X-linked 21) and scn4a (hyperkalemic peridoc paralysis), are particularly interesting for their essential role in these diseases, indicated by the "reliability score" of the gene-disease pair (Table 1). Based on this, we believe that our results open a promising possibility to design proper genetically modified animal models of neurological disorders aimed to investigate the molecular mechanisms that prevent the repair of vulnerable genes.

\section{Additional files}

Additional file 1: Table S1. Primers used for ChIP-qPCR in different rat genomic regions. (XLSX $62 \mathrm{~kb}$ )

Additional file 2: Figure S1. a UCSC browser images showing $\mathrm{\gamma H} 2 \mathrm{AX}$ binding around app/2 gene. $\mathbf{b}$ UCSC browser images corresponding to the mouse pcdh and krt loci located in chromosomes 11 and 18 respectively and their corresponding regions in the rat genome. Binding sites defined by ChIP-seq for cohesin subunits SMC1 and SA1, as well as for CTCF in mouse adult cortex are shown. Arrowheads show the position of the primers used for ChIP-qPCR performed with chromatin from rat cortical neurons. (JPG $1740 \mathrm{~kb}$ )

\section{Abbreviations}

ChIP: Chromatin immunoprecipitation; DDR: DNA damage response; DSBs: Double Strand breaks; IR: Ionizing radiation; NHEJ: Non-homologous end joining; OMIM: Online Mendelian Inheritance in Man; PDDF: Persistent DNA damage foci; TADs: Topologically Associated Domains

\section{Acknowledgements \\ Authors wish to thank Raquel García Ceballos and Daniel Giménez for technical assistance.}

\section{Funding}

This work was supported by the following grants: "Dirección General de Investigación" (BFU2014-54754-P) and "Centro de Investigación Biomédica en Red sobre Enfermedades Neurodegenerativas" (CIBERNED; CB06/05/0037) Spain.

\section{Authors' contributions}

Conception, design and funding: ML, MTB, AC. Acquisition and analysis of cell biology and biochemistry data: JMG, OT, IC, MTB, ML. ChIP experiments and bioinformatic analysis: $A C$. Drafting the manuscript: $M L, A C$. Critical revision of the manuscript: MTB, AC, ML. All authors read and approved the final manuscript.

\section{Ethics approval}

All procedures performed in the studies involving animal participants were in accordance with the ethical standards of the Council of the European Communities and current Spanish legislation, and the experiments were approved by the Bioethical Committee of the University of Cantabria.

\section{Competing interests}

The authors declare that they have no competing interests.

\section{Publisher's Note}

Springer Nature remains neutral with regard to jurisdictional claims in published maps and institutional affiliations.

\section{Author details}

${ }^{1}$ Department of Anatomy and Cell Biology and "Centro de Investigación Biomédica en Red sobre Enfermedades Neurodegenerativas" (CIBERNED), University of Cantabria-IDIVAL, Santander, Spain. ${ }^{2}$ Chromosome Dynamics Group, Molecular Oncology Program, Spanish National Cancer Research Centre (CNIO), 28029 Madrid, Spain. ${ }^{3}$ Present address: Department of Molecular Biology and CIBERNED, University of Cantabria-IDIVAL, Santander, 
Spain. ${ }^{4}$ Department of Anatomy and Cell Biology, Faculty of Medicine, Avd, Cardenal Herrera Oria sn, /39011 Santander, Spain.

\section{Received: 12 July 2018 Accepted: 19 July 2018}

Published online: 26 July 2018

\section{References}

1. Aguado C, Sarkar S, Korolchuk VI, Criado O, Vernia S, Boya P et al (2010) Laforin, the most common protein mutated in Lafora disease, regulates autophagy. Hum Mol Genet 19:2867-2876. https:/doi.org/10.1093/hmg/ddq190.

2. Akhmanova A, Verkerk T, Langeveld A, Grosveld F, Galjart N (2000) Characterisation of transcriptionally active and inactive chromatin domains in neurons. J Cell Sci 113(Pt 24):4463-4474.

3. Baltanás FC, Casafont I, Lafarga V, Weruaga E, Alonso JR, Berciano MT et al (2011) Purkinje cell degeneration in pcd mice reveals large scale chromatin reorganization and gene silencing linked to defective DNA repair. J Biol Chem 286:28287-28302. https://doi.org/10.1074/jbc.M111. 246041.

4. Bothmer A, Robbiani DF, Feldhahn N, Gazumyan A, Nussenzweig A, Nussenzweig MC (2010) 53BP1 regulates DNA resection and the choice between classical and alternative end joining during class switch recombination. J Exp Med 207:855-865. https://doi.org/10.1084/jem.20100244.

5. Canela A, Maman Y, Jung S, Wong N, Callen E, Day A et al (2017) Genome organization drives chromosome fragility. Cell 170:507-521.e18. https://doi. org/10.1016/j.cell.2017.06.034.

6. Cannon SC (2017) Sodium Channelopathies of skeletal muscle. Handb Exp Pharmacol 246:309-330. https://doi.org/10.1007/164_2017_52.

7. Casafont I, Palanca A, Lafarga V, Berciano MT, Lafarga M (2011) Effect of ionizing radiation in sensory ganglion neurons: organization and dynamics of nuclear compartments of DNA damage/repair and their relationship with transcription and cell cycle. Acta Neuropathol 122:481-493. https://doi.org/ 10.1007/s00401-011-0869-0

8. Chen Y, Henson ES, Xiao W, Shome E, Azad MB, Burton TR et al (2016) BCl-2 family member $\mathrm{Mcl}-1$ expression is reduced under hypoxia by the $\mathrm{E} 3$ ligase FBW7 contributing to BNIP3 induced cell death in glioma cells. Cancer Biol Ther 17:604-613. https://doi.org/10.1080/15384047.2015.1095399.

9. Chiesa A, Crisafulli C, Porcelli S, Balzarro B, Han C, Patkar AA et al (2012) Case-control association study of GRIA1, GRIA2 and GRIA4 polymorphisms in bipolar disorder. Int J Psychiatry Clin Pract 16:18-26. https://doi.org/10. 3109/13651501.2011.617459.

10. Chiesa A, Crisafulli C, Porcelli S, Han C, Patkar AA, Lee SJ et al (2012) Influence of GRIA1, GRIA2 and GRIA4 polymorphisms on diagnosis and response to treatment in patients with major depressive disorder. Eur Arch Psychiatry Clin Neurosci 262:305-311. https://doi.org/10.1007/s00406-011-0270-y.

11. Chiesa A, Lia L, Lia C, Lee S-J, Han C, Patkar AA et al (2013) Investigation of possible epistatic interactions between GRIA2 and GRIA4 variants on clinical outcomes in patients with major depressive disorder. J Int Med Res 41:809815. https://doi.org/10.1177/0300060513477295.

12. Chiolo I, Minoda A, Colmenares SU, Polyzos A, Costes SV, Karpen GH (2011) Double-strand breaks in heterochromatin move outside of a dynamic HP1a domain to complete recombinational repair. Cell 144:732-744. https://doi. org/10.1016/j.cell.2011.02.012.

13. Chow HM, Herrup K (2015) Genomic integrity and the ageing brain. Nat Rev Neurosci:672-684. https://doi.org/10.1038/nrn4020

14. Coy JF, Dressler D, Wilde J, Schubert P (2005) Mutations in the transketolase-like gene TKTL1: clinical implications for neurodegenerative diseases, diabetes and cancer. Clin Lab 51:257-273.

15. Crowther DC (2002) Familial conformational diseases and dementias. Hum Mutat 20:1-14. https://doi.org/10.1002/humu.10100.

16. Cuadrado A, Remeseiro S, Graña O, Pisano DG, Losada A (2015) The contribution of cohesin-SA1 to gene expression and chromatin architecture in two murine tissues. Nucleic Acids Res 43:3056-3067. https://doi.org/10. 1093/nar/gkv144.

17. Dixon JR, Selvaraj S, Yue F, Kim A, Li Y, Shen Y et al (2012) Topological domains in mammalian genomes identified by analysis of chromatin interactions. Nature 485:376-380. https://doi.org/10.1038/nature1 1082.

18. Drgon T, Zhang P-W, Johnson C, Walther D, Hess J, Nino M et al (2010) Genome wide association for addiction: replicated results and comparisons of two analytic approaches. PLoS One 5:e8832. https://doi.org/10.1371/ journal.pone.0008832.
19. Fernandez-Capetillo O, Lee A, Nussenzweig M, Nussenzweig A (2004) H2AX: the histone guardian of the genome. DNA Repair (Amst) 3:959-967. https:// doi.org/10.1016/j.dnarep.2004.03.024.

20. Ferrari R, Hernandez DG, Nalls MA, Rohrer JD, Ramasamy A, Kwok JBJ et al (2014) Frontotemporal dementia and its subtypes: a genome-wide association study. Lancet Neurol 13:686-699. https://doi.org/10.1016/S14744422(14)70065-1.

21. Ferrer I, Serrano T, Alcantara S, Tortosa A, Graus F (1993) X-ray-induced cell death in the developing hippocampal complex involves neurons and requires protein synthesis. J Neuropathol Exp Neurol 52:370-378. https://doi. org/10.1097/00005072-199307000-00004.

22. Fielder $E$, von Zglinicki T, Jurk D (2017) The DNA damage response in neurons: die by apoptosis or survive in a senescence-like state? J Alzheimers Dis 60:S107-S131. https://doi.org/10.3233/JAD-161221.

23. Galbiati A, Beauséjour C, d'Adda di Fagagna F (2017) A novel single-cell method provides direct evidence of persistent DNA damage in senescent cells and aged mammalian tissues. Aging Cell 16:422-427. https://doi.org/ 10.1111/acel.12573.

24. Ganesh S, Delgado-Escueta AV, Sakamoto T, Avila MR, Machado-Salas J, Hoshii $Y$ et al (2002) Targeted disruption of the Epm2a gene causes formation of Lafora inclusion bodies, neurodegeneration, ataxia, myoclonus epilepsy and impaired behavioral response in mice. Hum Mol Genet 11: 1251-1262.

25. Gaudy-Marqueste C, Roll P, Esteves-Vieira V, Weiller P-J, Grob JJ, Cau P et al (2010) LBR mutation and nuclear envelope defects in a patient affected with Reynolds syndrome. J Med Genet 47:361-370. https://doi.org/10.1136/ jmg.2009.071696.

26. Gómez-Herreros F, Schuurs-Hoeijmakers JHM, McCormack M, Greally MT, Rulten S, Romero-Granados R et al (2014) TDP2 protects transcription from abortive topoisomerase activity and is required for normal neural function Nat Genet 46:516-521. https://doi.org/10.1038/ng.2929.

27. Gout JF, Li W, Fritsch C, Li A, Haroon S, Singh L et al (2017) The landscape of transcription errors in eukaryotic cells. Sci Adv 3:e1701484. https://doi. org/10.1126/sciadv. 1701484.

28. Guo Y, Xu Q, Canzio D, Shou J, Li J, Gorkin DU et al (2015) CRISPR inversion of CTCF sites alters genome topology and enhancer/promoter function. Cell 162:900-910. https://doi.org/10.1016/j.cell.2015.07.038.

29. Harding SM, Boiarsky JA, Greenberg RA (2015) ATM dependent silencing links nucleolar chromatin reorganization to DNA damage recognition. Cell Rep 13:251-259. https://doi.org/10.1016/j.celrep.2015.08.085.

30. Hayashi T, Yoshida T, Ra M, Taguchi R, Mishina M (2013) IL1RAPL1 associated with mental retardation and autism regulates the formation and stabilization of glutamatergic synapses of cortical neurons through RhoA signaling pathway. Mei L, editor. PLoS One 8:e66254. https://doi.org/10. 1371/journal.pone.0066254.

31. Henriksson S, Rassoolzadeh $\mathrm{H}$, Hedström E, Coucoravas C, Julner A, Goldstein M et al (2014) The scaffold protein WRAP53 $\beta$ orchestrates the ubiquitin response critical for DNA double-strand break repair. Genes Dev 28:2736-2738. https://doi.org/10.1101/gad.246546.114.

32. Hernandez-Verdun D, Roussel P, Thiry M, Sirri V, Lafontaine DLJ (2010) The nucleolus: structure/function relationship in RNA metabolism. Wiley Interdiscip. Rev. RNA:415-431. https://doi.org/10.1002/wrna.39.

33. Ismail IH, Hendzel MJ (2008) The gamma-H2A.X: is it just a surrogate marker of double-strand breaks or much more? Environ Mol Mutagen 49:73-82. https://doi.org/10.1002/em.20358.

34. Isoniemi A, Hietala M, Aula P, Jalanko A, Peltonen L (1995) Identification of a novel mutation causing aspartylglucosaminuria reveals a mutation hotspot region in the aspartylglucosaminidase gene. Hum Mutat 5:318-326. https:// doi.org/10.1002/humu.1380050408.

35. Jakob B, Splinter J, Conrad S, Voss KO, Zink D, Durante M et al (2011) DNA double-strand breaks in heterochromatin elicit fast repair protein recruitment, histone H2AX phosphorylation and relocation to euchromatin. Nucleic Acids Res 39:6489-6499. https://doi.org/10.1093/nar/gkr230.

36. Jangi M, Fleet C, Cullen P, Gupta SV, Mekhoubad S, Chiao E et al (2017) SMN deficiency in severe models of spinal muscular atrophy causes widespread intron retention and DNA damage. Proc Natl Acad Sci 114: E2347-E2356. https://doi.org/10.1073/pnas.1613181114.

37. Katyal S, Lee Y, Nitiss KC, Downing SM, Li Y, Shimada M et al (2014) Aberrant topoisomerase-1 DNA lesions are pathogenic in neurodegenerative genome instability syndromes. Nat Neurosci 17:813-821. https://doi.org/10.1038/nn.3715. 
38. Krawczyk PM, Borovski T, Stap J, Cijsouw T, ten Cate R, Medema JP et al (2012) Chromatin mobility is increased at sites of DNA double-strand breaks. J Cell Sci 125:2127-2133. https://doi.org/10.1242/jcs.089847.

39. Kruhlak MJ, Celeste A, Dellaire G, Fernandez-Capetillo O, Müller WG, McNally JG et al (2006) Changes in chromatin structure and mobility in living cells at sites of DNA double-strand breaks. J Cell Biol 172:823-834. https://doi.org/ 10.1083/jcb.200510015

40. Lee H-K, Takamiya K, Han J-S, Man H, Kim C-H, Rumbaugh G et al (2003) Phosphorylation of the AMPA receptor GluR1 subunit is required for synaptic plasticity and retention of spatial memory. Cell 112:631-643.

41. Lieber MR (2010) The mechanism of double-strand DNA break repair by the nonhomologous DNA end-joining pathway. Annu Rev Biochem 79:181-211. https://doi.org/10.1146/annurev.biochem.052308.093131.

42. Lin H, Lei Y, Zhang B, Dai Z, Lu X (2015) Common variants of HTR1A and SLC6A4 confer the increasing risk of schizophrenia susceptibility: a population-based association and epistasis analysis. Am J Med Genet B Neuropsychiatr Genet 168:749-755. https://doi.org/10.1002/ajmg.b.32380.

43. Lombard DB, Chua KF, Mostoslavsky R, Franco S, Gostissa M, Alt FW (2005) DNA repair, genome stability, and aging. Cell 120:497-512. https://doi.org/ 10.1016/j.cell.2005.01.028

44. Lovell MA, Markesbery WR (2007) Oxidative DNA damage in mild cognitive impairment and late-stage Alzheimer's disease. Nucleic Acids Res 35:74977504. https://doi.org/10.1093/nar/gkm821.

45. Lu T, Pan Y, Kao SY, Li C, Kohane I, Chan J et al (2004) Gene regulation and DNA damage in the ageing human brain. Nature 429:883-891. https://doi. org/10.1038/nature02661.

46. Lupiáñez DG, Kraft K, Heinrich V, Krawitz P, Brancati F, Klopocki E et al (2015) Disruptions of topological chromatin domains cause pathogenic rewiring of gene-enhancer interactions. Cell 161:1012-1025. https://doi.org/10.1016/j. cell.2015.04.004.

47. Madabhushi R, Gao F, Pfenning AR, Pan L, Yamakawa S, Seo J et al (2015) Activity-induced DNA breaks govern the expression of neuronal early-response genes. Cell 161:1592-1605. https://doi.org/10.1016/j.cell.2015.05.032.

48. Madabhushi R, Pan L, Tsai LH (2014) DNA damage and its links to neurodegeneration. Neuron:266-282. https://doi.org/10.1016/j.neuron. 2014.06.034.

49. Martou G, De Boni U (2000) Nuclear topology of murine, cerebellar Purkinje neurons: changes as a function of development. Exp Cell Res 256:131-139. https://doi.org/10.1006/excr.1999.4793.

50. Mata-Garrido J, Casafont I, Tapia O, Berciano MT, Lafarga M (2016) Neuronal accumulation of unrepaired DNA in a novel specific chromatin domain: structural, molecular and transcriptional characterization. Acta Neuropathol Commun 4:41. https://doi.org/10.1186/s40478-016-0312-9.

51. Matsuo N, Reijmers L, Mayford M (2008) Spine-type-specific recruitment of newly synthesized AMPA receptors with learning. Science 319:1104-1107. https://doi.org/10.1126/science.1149967.

52. Mckinnon PJ (2013) Maintaining genome stability in the nervous system Nat Neurosci 16:1523-1529. https://doi.org/10.1038/nn.3537.

53. Misteli T, Soutoglou E (2009) The emerging role of nuclear architecture in DNA repair and genome maintenance. Nat Rev Mol Cell Biol 10:243-254. https://doi.org/10.1038/nrm2651.

54. Nora EP, Goloborodko A, Valton AL, Gibcus JH, Uebersohn A, Abdennur N et al (2017) Targeted degradation of CTCF decouples local insulation of chromosome domains from genomic compartmentalization. Cell 169:930944.e22. https://doi.org/10.1016/j.cell.2017.05.004.

55. Nora EP, Lajoie BR, Schulz EG, Giorgetti L, Okamoto I, Servant N et al (2012) Spatial partitioning of the regulatory landscape of the X-inactivation Centre. Nature 485:381-385. https://doi.org/10.1038/nature11049.

56. Nouspikel T (2007) DNA repair in differentiated cells: some new answers to old questions. Neuroscience:1213-1221. https://doi.org/10.1016/j. neuroscience.2006.07.006.

57. Nouspikel T, Hanawalt PC (2002) DNA repair in terminally differentiated cells. DNA Repair (Amst) 1:59-75. https://doi.org/10.1016/S15687864(01)00005-2.

58. Palanca A, Casafont I, Berciano MT, Lafarga M (2014) Proteasome inhibition induces DNA damage and reorganizes nuclear architecture and protein synthesis machinery in sensory ganglion neurons. Cell Mol Life Sci 71:19611975. https://doi.org/10.1007/s00018-013-1474-2.

59. Pan L, Penney J, Tsai L-H (2014) Chromatin regulation of DNA damage repair and genome integrity in the central nervous system. J Mol Biol 426: 3376-3388. https://doi.org/10.1016/j.jmb.2014.08.001.
60. Panier S, Boulton SJ (2014) Double-strand break repair: 53BP1 comes into focus. Nat Rev Mol Cell Biol. 15:7-18. https://doi.org/10.1038/nrm3719.

61. Pena E, Berciano MT, Fernandez R, Ojeda JL, Lafarga M (2001) Neuronal body size correlates with the number of nucleoli and Cajal bodies, and with the organization of the splicing machinery in rat trigeminal ganglion neurons. J Comp Neurol 430:250-263. https://doi.org/10.1002/10969861(20010205)430:2<250::AID-CNE1029>3.0.CO;2-L.

62. Peters A, Palay S (1991) H deF W. The fine structure of the nervous system. Neurons and their suppoting cells. Oxford University Press, New York.

63. Pisanu C, Preisig M, Castelao E, Glaus J, Pistis G, Squassina A et al (2017) A genetic risk score is differentially associated with migraine with and without aura. Hum Genet 136:999-1008. https://doi.org/10. 1007/s00439-017-1816-5.

64. Politz JCR, Scalzo D, Groudine M (2013) Something silent this way forms: the functional organization of the repressive nuclear compartment. Annu Rev Cell Dev Biol 29:241-270. https://doi.org/10.1146/annurev-cellbio101512-122317.

65. Ramírez F, Ryan DP, Grüning B, Bhardwaj V, Kilpert F, Richter AS et al (2016) deepTools2: a next generation web server for deep-sequencing data analysis. Nucleic Acids Res 44:W160-W165. https://doi.org/10.1093/nar/gkw257.

66. Ramos-Brossier M, Montani C, Lebrun N, Gritti L, Martin C, Seminatore-Nole C et al (2015) Novel IL1RAPL1 mutations associated with intellectual disability impair synaptogenesis. Hum Mol Genet 24:1106-1118. https://doi. org/10.1093/hmg/ddu523.

67. Rass U, Ahel I, West SC (2007) Defective DNA repair and neurodegenerative disease. Cell 130:991-1004. https://doi.org/10.1016/j.cell.2007.08.043.

68. Rice JC, Briggs SD, Ueberheide B, Barber CM, Shabanowitz J, Hunt DF et al (2003) Histone methyltransferases direct different degrees of methylation to define distinct chromatin domains. Mol Cell 12:1591-1598. https://doi.org/ 10.1016/S1097-2765(03)00479-9.

69. Sanders LH, McCoy J, Hu X, Mastroberardino PG, Dickinson BC, Chang CJ et al (2014) Mitochondrial DNA damage: molecular marker of vulnerable nigral neurons in Parkinson's disease. Neurobiol Dis 70:214-223. https://doi.org/ 10.1016/j.nbd.2014.06.014.

70. Sanderson DJ, Lee A, Sprengel R, Seeburg PH, Harrison PJ, Bannerman DM (2017) Altered balance of excitatory and inhibitory learning in a genetically modified mouse model of glutamatergic dysfunction relevant to schizophrenia. Sci Rep 7:1765. https://doi.org/10.1038/ s41598-017-01925-8.

71. Schmidt D, Schwalie PC, Wilson MD, Ballester B, Gonalves $\hat{A}$, Kutter $C$ et al (2012) Waves of retrotransposon expansion remodel genome organization and CTCF binding in multiple mammalian lineages. Cell 148:335-348. https://doi.org/10.1016/j.cell.2011.11.058.

72. Schwer B, Wei P-C, Chang AN, Kao J, Du Z, Meyers RM et al (2016) Transcription-associated processes cause DNA double-strand breaks and translocations in neural stem/progenitor cells. Proc Natl Acad Sci 113:2258-2263. https:/doi.org/10.1073/pnas.1525564113.

73. Sedelnikova OA, Horikawa I, Zimonjic DB, Popescu NC, Bonner WM, Barrett JC (2004) Senescing human cells and ageing mice accumulate DNA lesions with unrepairable double-strand breaks. Nat Cell Biol 6:168-170. https://doi. org/10.1038/ncb1095.

74. Suberbielle E, Sanchez PE, Kravitz AV, Wang X, Ho K, Eilertson K et al (2013) Physiologic brain activity causes DNA double-strand breaks in neurons, with exacerbation by amyloid- $\beta$. Nat Neurosci 16:613-621. https://doi.org/10. 1038/nn.3356

75. Takada M, Zhang W, Suzuki A, Kuroda TS, Yu Z, Inuzuka H et al (2017) FBW7 loss promotes chromosomal instability and tumorigenesis via cyclin E1/ CDK2-mediated phosphorylation of CENP-A. Cancer Res 77:4881-4893. https://doi.org/10.1158/0008-5472.CAN-17-1240.

76. Torres-Rosell J, Sunjevaric I, De Piccoli G, Sacher M, Eckert-Boulet N, Reid R et al (2007) The Smc5-Smc6 complex and SUMO modification of Rad52 regulates recombinational repair at the ribosomal gene locus. Nat Cell Bio 9:923-931. https://doi.org/10.1038/ncb1619.

77. Udina M, Navinés R, Egmond E, Oriolo G, Langohr K, Gimenez D et al (2016) Glucocorticoid receptors, brain-derived neurotrophic factor, serotonin and dopamine neurotransmission are associated with interferon-induced depression. Int J Neuropsychopharmacol 19. https://doi.org/10.1093/ijnp/pyv135.

78. Wang K, Zhang H, Ma D, Bucan M, Glessner JT, Abrahams BS et al (2009) Common genetic variants on 5p14.1 associate with autism spectrum disorders. Nature 459:528-533. https://doi.org/10.1038/nature07999. 
79. White RR, Vijg J (2016) Do DNA double-strand breaks drive aging? Mol Cell 63:483-495. https://doi.org/10.1016/j.molcel.2016.08.004.

80. Yin Y, Liu Y, Pan X, Chen R, Li P, Wu HJ et al (2016) Interleukin-1 $\beta$ promoter polymorphism enhances the risk of sleep disturbance in Alzheimer's disease. PLoS One 11:e0149945. https://doi.org/10.1371/journal.pone.0149945.

81. Zimmermann M, De Lange T (2014) 53BP1: pro choice in DNA repair. Trends Cell Biol 24:108-117. https://doi.org/10.1016/j.tcb.2013.09.003.

Ready to submit your research? Choose BMC and benefit from:

- fast, convenient online submission

- thorough peer review by experienced researchers in your field

- rapid publication on acceptance

- support for research data, including large and complex data types

- gold Open Access which fosters wider collaboration and increased citations

- maximum visibility for your research: over $100 \mathrm{M}$ website views per year

At BMC, research is always in progress.

Learn more biomedcentral.com/submissions 